\title{
Studi Pengaruh Orientasi Serat Fiber Glass Searah dan Dua Arah Single Layer terhadap Kekuatan Tarik Bahan Komposit Polypropylene
}

\author{
Munasir \\ Jurusan Fisika FMIPA, Universitas Negeri Suarabaya \\ e-mail : munasirmsc@yahoo.com
}

\begin{abstract}
Abstrak
Telah dilakukan fabrikasi dan uji kekuatan tarik bahan komposit Polypropylene (matrik) dengan Fiber Glass (sebagai penguat/filler) dengan perbandingan $95 \%$ dan 5\% (matrix: filler), dengan filler tersusun secara singledirectional dan bidirectional dengan single layer. Massa keseluruhan dari sampel adalah 4 gram. Dari sampel yang sudah dibuat dilakukan uji kompaktibilitas untuk menetukan kekompakan ikatan antar muka antara matrik dan fillernya, dan juga dilakukan uji optimasi pemanasan untuk menentukan temperatur pembakaran yang paling optimum sehingga dihasilkan bahan komposit dengan sifat mekanik / kekuatan tarik terbesar. Berdasarkan uji kualitas ikatan antar muka atau kompaktibilitas komposit polypropylene dengan fiber Glass secara teoritis sudah terjadi kompaktibilitas antara kedua bahan tersebut sehingga membentuk bahan komposit, hal ini ditunjukan oleh grafik upper lower bond. Dan dari hasil uji kekuatan tarik diperoleh, kekuatan tarik terbesar terdapat pada bahan komposit dengan orientasi serat searah dibanding komposit tanpa serat $(1,06: 1)$ dan tanpa serat dibanding serat dua arah (1:0,87). Komposit dengan serat dua arah mempunyai kekuatan tarik terendah, hal ini disebabkan oleh arah serat yang tegak lurus dengan arah pembebanan akan memperlemah kekuatan tariknya, hal ini berkebalikan dengan nilai elogationnya yaitu orientasi serat dua arah mempunyai elongation yang lebih besar daripada serat searah. Selanjutnya disarankan untuk penelitian berikutnya, bahwa dalam pembuatan sampel uji diharapkan menggunakan alat yang dapat mengontrol suhu (stabil) dan dapat dilakukan untuk bahan komposit multilayer dengan perbedaan orientasi serat pada tiap lapisnya.
\end{abstract}

Kata Kunci : PP, Fiber glass, komposit, uji tarik 


\section{Pendahuluan}

Dewasa ini pengetahuan ilmu bahan memegang peranan yang sangat penting dalam dunia industri, terutama industri yang bergerak dalam bidang manufaktur. Dimana lebih dari 60\% harga pokok penjualan atau biaya produksi berasal dari komponen material.

Saat ini bahan yang banyak menjadi obyek penelitian adalah beberapa jenis plastik seperti polyetilen, polypropylene, LDPE, PVC dan lainya. Dengan merekayasa sifat bahan dasar yang mampu menjadikan bahan tersebut menjadi bahan baku yang lebih unggul dari masing-masing elemen penyusun. Dengan kemajuan dibidang komposit ini, maka terbuka peluang untuk membuka bahan-bahan baru, survei mencakup komoditi plastik volume besar, plastik murah dan plastik untuk rekayasa serta plastik modern. Termoplastik yang mendominasi pasaran (misalnya: PE, PVC, dan PP) pengembangan tipe plastik yang sama sekali baru sangat mahal.[Asrori,2000:06].

Pada penelitian sebelumnya mengenai sifat dari polypropylene dan penelitian tentang komposit polyester berpenguat serat bambu dengan membedakan orientasi seratnya. Karena itu penulis berusaha mengadakan penelitian tentang sifat mekanik komposit polimer pada polypropylene yang berpenguat fiber glass. Fiber glass merupakan sebuah material yang terbuat dari fiber yang sangat bagus dari gelas. Fiber glass digunakan memproduksi insulasi dan tekstil serta sebagai agen penguat untuk jenis produk plastik. Bahan komposit dengan pengisi fiber glass ini dapat digunakan sebagai pengganti besi dalam kapal, pagar, dan bumper mobil, dimana material ini mempunyai massa yang jauh lebih ringan, kekuatan tarik dan penekanan yang besar daripada besi. Dari bahan tersebut diharapkan dapat dihasilkan kombinasi sifat komposit polimer yang diunggulkan dari keduanya. Komposit merupakan gabungan dua bahan atau lebih untuk membentuk bahan baru yang mempunyai sifat berbeda dari sifat penyusunya. Penelitian terutama ditujukan untuk meningkatkan dan menekan biaya material yang sudah mapan seperti: memperbaiki katalis polimerisasi, komposit, karet termoplastik dan daur ulang limbah. Komposit polimer berpenguat fiber glass adalah salah satunya, dimana serat digunakan untuk filler sebagai pengisinya. Material komposit berpenguat serat gelas dikenal sebagai plastik berpenguat gelas (Glass reinforced plastik, GRP) atau epoxy diperkuat gelas fiber(GRE). [Sudira \&Sinroku, 1999:437].

Berdasarkan latar belakang yang diuraikan diatas maka dapat dirumuskan permasalahan sebagai kajian didalam penelitian sebagai berikut: "Bagaimanakah pengaruh orientasi serat fiber glass searah dan dua arah single layer terhadap sifat mekanik komposit polimer polypropylene?".

Adapun tujuan dilakukan penelitian ini adalah untuk mengetahui kekuatan tarik terutama kekuatan tarik pada polypropylene berpenguat fiber glass dengan orientasi searah dan dua arah single layer.

Manfaat yang diharapkan dari penelitian ini digunakan sebagai:

a. Panduan dan pandangan yang tepat bagi masyarakat ataupun industri yang bergerak dalam bidang polimer, terutama plastik.

b. Tambahan pengetahuan yang nyata mengenai bahan komposit polimer polypropylene bagi peneliti, mahasiswa dan pembaca pada umumnya.

c. Mencari orientasi serat yang tepat pada komposit polimer polypropylene dengan sifat mekanik yang baik, terutama kekuatan tarik.

Definisi Operasional, agar tidak terjadi kesalahan penafsiran tentang istilahistilah, maka penulis menggunakan definisi sebagai berikut: (a) Polypropylene adalah jenis bahan termoplastik yang digunakan sebagai karung plastik, botol plastik, bak accu serta peralatan rumah tangga. (b) 
Fiber glass adalah serat sintetik sebagai bahan penguat atau filler pada polimer, dalam penelitian ini digunakan serat gelas berjenis E dan berbentuk Chooped Strand Mat .

Asumsi, dalam penelitian ini diasumsikan bahwa: (a) pada saat penataan serat didalam cetakan tidak terjadi perubahan ikatan kimia pada matrik, (b) pemanasan menggunakan setrika agar terjaga kestabilan suhu pada bahan dalam proses pelelehan, (c) penutupan pada cetakan dimaksudkan agar suhu terjaga kestabilanya didaerah sampel saat pemanasan, (d) serat dianggap lurus dalam matrik.

Batasan Masalah, agar penelitian ini berjalan dengan efektif dan efisien maka penelitian ini dibatasi oleh: (a) tidak membahas reaksi kimia, (b) komposisi bahan matrik dan serat gelas dibuat tetap yaitu $95 \%$ fraksi bahan matrik dan 5\% fraksi filler. (c) analisa perilaku bahan komposit ditinjau secara makro mekanik, (d) dalam penelitian ini sifat mekanik hanya dititikberatkan pada nilai kekuatan tarik.
2. Kajian Teori

Uji Kualitas Kompaktibilitas Komposit Polypropylene dengan Fiber Glass.

Dalam penelitian ini terlebih dahulu dianalisis secara teoritis adanya ikatan antar muka atau kompaktibilitas komposit isotropik Polypropylene dengan Fiber Glass sebagai berikut:

a. Menghitung Modulus Elastisitas filler model kubus, dengan Persamaan Halpin-Tsen :

$$
\frac{E c}{E m}=\frac{E m+(E f-E m) V f^{2 / 3}}{E m+(E f-E m) V f^{2 / 3}\left(1-V f^{1 / 3}\right)}
$$

b. Menghitung Upper Bond dengan hukum Pencampuran Stress Longitudinal: $\quad E c=E f . V f+E m . V m$

c. Menghitung Lower Bond berdasarkan modulus Elastisitas Tranvesal. Dengan menggunakan persamaan : $\quad \frac{1}{E c}=$ $\frac{V f}{E f}+\frac{V m}{E m}$

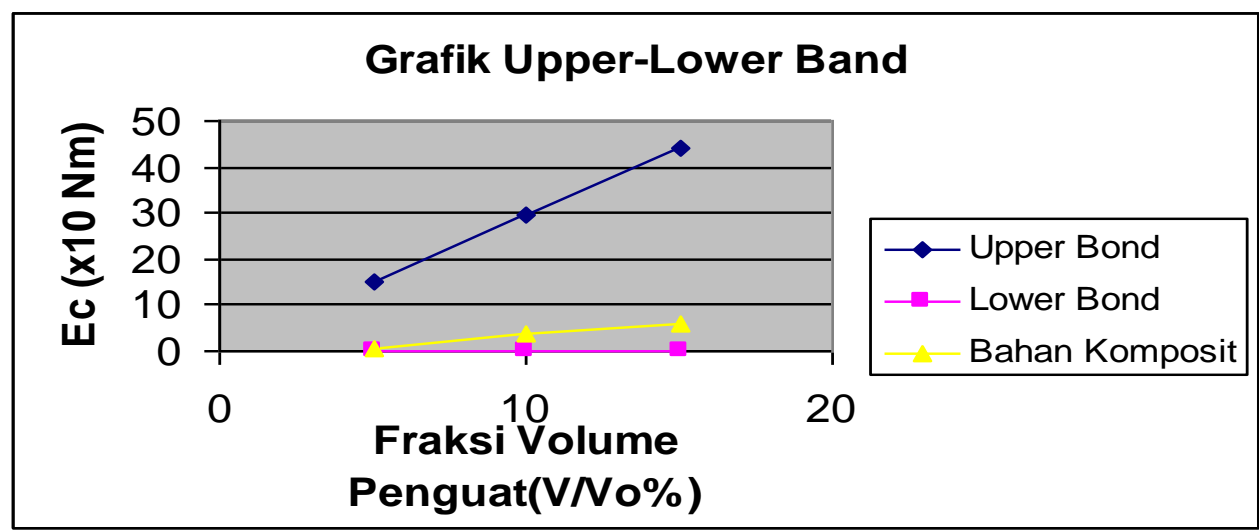

Gambar 1. Uji kualitas Ikatan Antar Muka Komposit Polypropylene dengan fiber Glass

Pengaruh lama pemanasan pada Polypropylene

Suhu dan lama pemanasan berpengaruh pada sifat mekanik bahan. Pada penelitian sebelumnya [Penelitian oleh Nuriana Ulfa:2006], diperoleh hasil pengaruh lamanya pemanasan terhadap uji tarik bahan polypropylene.

Lama pemanasan yang mengakibatkan nilai kekuatan tarik terbesar pada waktu 30 menit. Untuk lama pemanasan 50 menit tidak diperoleh kekuatan tarik disebabkan 
keadaan fisik dari sampel tidak memenuhi untuk pengujian yaitu terdapat kegetasan. Dari grafik diatas dapat disimpulkan daerah dengan kekuatan tarik yang baik pada selang waktu 25-40 menit. Sebagai perbandingan dalam penelitian ini, untuk sampel uji dengan lama pemanasan 35 menit didapat kekuatan tariknya sebesar 5,39 kgf m-2. Keadaan tersebut menyimpulkan bahwa nilai kekuatan tarik polimer polypropylene jenis Masplene 5402 terdapat pada lama pemanasan 30 menit. Maka pada penelitian ini, peneliti menggunakan waktu lamanya pemanasan 30 menit sehingga diharapkan didapat hasil yang maksimal.

\section{Metode Penelitian}

Dalam penelitian ini yang menjadi variabel terikatnya adalah sifat mekanik yaitu uji tarik dari PP yang berpenguat fiber glass, sedangkan variabel manipulasinya adalah orientasi penguat fiber glass yaitu satu arah dan dua arah single layer.

\section{Bahan Penelitian}

Bahan dasar yang digunakan dalam penelitian ini adalah: (a)
Polypropylene, sebagai bahan dasar atau sebagai matrik komposit, (b) Serat Gelas atau fiber Glass sebagai penguat atau filler. Fiber glass yang digunakan berjenis E-glass dengan bentuk serat Chooped Strand Mat (gambar 2).

\section{Alat yang Digunakan}

Alat yang digunakan adalah: (1) beker Glass, sebagai tempat untuk mencair bahan dasar selain cetakan, (2) pengaduk atau spatula, alat ini terbuat dari aluminium dan digunakan untuk menata dan memindahkan polypropylene ke cetakan, (3) setrika, sebagai pemanas dalam proses pelelehan bahan, (4) cetakan, alat cetak yang terbuat dari besi dengan tujuan agar panas yang dihantarkan cepat, merata dan titik leleh dari cetakan lebih tinggi dari polimer (bahan uji) untuk membentuk bahan sesuai dengan standart alat uji, (5) timbangan, digunakan untuk mmengetahui berat serat gelas, matrik dan sampel, (6) statis, alat yang digunakan sebagai menggantungkan termometer, (7) termometer, alat yang digunakan untuk mengukur suhu dalam proses pemanasan dan pendinginan, (8) alat uji tarik standart JIS (Japan International Standard).

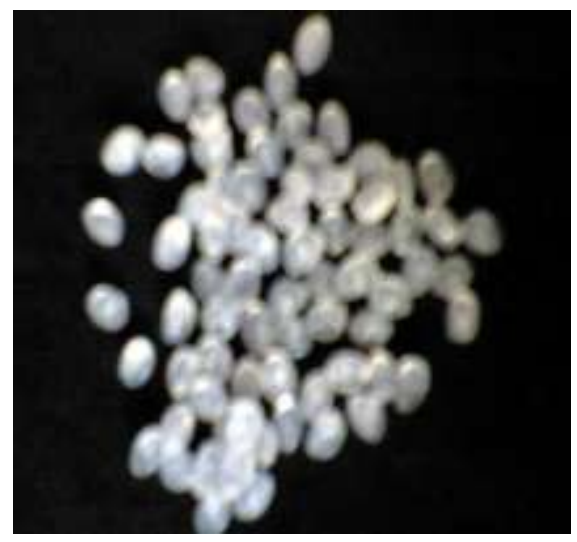

Gambar 2. (a) Serat gelas jenis E-Glass Chooped Strand Mat,

(b) Polypropylene jenis Masplene 5402

\section{Prosedur Penelitian}

Dalam penelitian ini, pembuatan sampel dilakukan dengan terlebih dahulu menentukan massa matrik dan filler. Komposisi matrik $95 \%$ dan filler 5\% dari massa bahan sampel keseluruhan. 
Massa sampel keseluruhan adalah 4 gram, sesuai dengan muatan massa maksimum cetakan dengan butiran polypropylene sebelum dilelehkan atau panaskan. Memanasi cetakan hingga suhu stabil sebelum memasukan bahan. Pada beberapa menit yaitu suhu stabil $\left(158^{\circ} \mathrm{C}\right)$, matrik $(\mathrm{PP})$ dipanaskan didalam cetakan diatas pemanas dan sebagian (PP) pada gelas beker dengan lama pemanasan 15 menit. Dalam waktu pemanasan (dalam keadaan sudah meleleh), kemudian dilakukan penataan serat gelas dan menutupinya dengan PP (matrik) yang telah dipanaskan dalam beker glass. Membiarkan PP dalam cetakan untuk pembekuan selama 26 menit.

\section{Hasil dan Pembahasan}

Hasil penelitian berupa kekuatan tarik bahan komposit Polypropylene (matrik) dengan Fiber Glass (sebagai penguat/filler) dengan perbandingan 95\% dan 5\% (matrix: filler), komposit berbentuk bidirectional single layer. Massa keseluruhan dari sampel adalah 4 gram. Alat cetak dibuat dari baja karena titik leleh baja lebih besar daripada titik leleh polimer. Polypropylene dilelehkan dengan suhu yang tertentu. Dengan terlebih dahulu memanaskan penutup cetakan dan cetakan sampel sampai suhu stabil/konstan. Pemanasan cetakan sampel ini dilakukan sedemikian sehingga diperoleh suhu yang sama antara bagian atas cetakan, bagian tengah dan juga penutup cetakan.

\section{Bentuk fisik sampel yang akan diuji tarik}

Sampel dibuat dari bahan dasar polypropylene (termoplastik), dengan lama pemanasan 15 menit dan pendinginan selama 30 menit dalam cetakan. Pembuatan sampel secara keseluruhan dilakukan dengan metode seperti diatas. Sampel terdiri dari : (a) sampel tanpa serat, yang terlihat putih seperti warna bahan semula, (b) sampel dengan serat, warna sampel terlihat kekuningan dikarenakan pengaruh penambahan filler (fiber optik) pada matrik dengan orientasi serat searah, dan (c). sampel dengan serat, warna sampel terlihat kekuningan dikarenakan pengaruh penambahan filler (fiber optik) pada matrik dengan orientasi serat dua arah. Untuk sampel (b) dan (c) berjenis single layer, dan semua sampel yang dihasilkan berupa tidak ada gelembung udara atau rongga udara didalamnya. Sampel-sampel tersebut secara fisik dapat dilihat pada gambar 3 berikut:

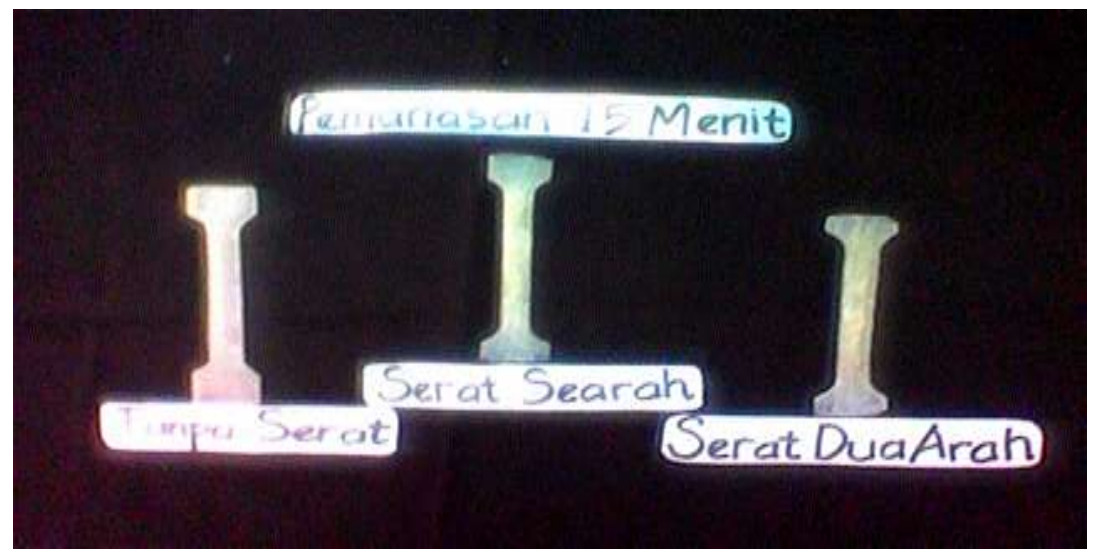

Gambar 3. Sampel dengan lama pemanasan 15 menit 
ISSN: 2087-9946

\section{Hasil dan pembahasan uji tarik komposit}

Hasil uji tarik komposit tanpa serat, serat searah dan dua arah single layer adalah sebagai berikut:

Tabel 1 Tensile Report Form sampel komposit polypropylene dengan tanpa serat

\begin{tabular}{|c|c|c|c|c|c|c|}
\hline \multirow{2}{*}{ Sampel } & \multirow{2}{*}{$\begin{array}{c}\text { Length } \\
(\mathrm{mm})\end{array}$} & \multicolumn{4}{|c|}{ Peak } & \multirow{2}{*}{ Elongation } \\
\cline { 3 - 7 } & & $\mathrm{kgf}$ & $\mathrm{N}$ & $\mathrm{Kgf} / \mathrm{mm} 2$ & $\begin{array}{c}\mathrm{N} / \mathrm{m} 2 \times 10 \\
6\end{array}$ & \\
\hline 1. & 65.00 & 425.86 & 4175.92 & 5.46 & 53.54 & 4.23 \\
2. & 65.00 & 432.62 & 4242.21 & 5.55 & 54.43 & 8.40 \\
\hline
\end{tabular}

Tabel 2. Tensile Report Form sampel komposit polypropylene dengan serat searah

\begin{tabular}{|c|c|c|c|c|c|c|}
\hline \multirow{2}{*}{ Sampel } & \multirow{2}{*}{$\begin{array}{c}\text { Length } \\
(\mathrm{mm})\end{array}$} & \multicolumn{4}{|c|}{ Peak } & \multirow{2}{*}{ Elongation } \\
\cline { 3 - 7 } & & $\mathrm{kgf}$ & $\mathrm{N}$ & $\mathrm{Kgf} / \mathrm{mm} 2$ & $\begin{array}{c}\mathrm{N} / \mathrm{m} 2 \times 10 \\
6\end{array}$ & \\
\hline 1. & 65.00 & 457.13 & 4482.55 & 5.86 & 53.54 & 0.58 \\
2. & 65.00 & 452.90 & 4441.07 & 5.81 & 54.43 & 0.58 \\
\hline
\end{tabular}

Tabel 3 Tensile Report Form sampel komposit polypropylene dengan serat dua arah

\begin{tabular}{|c|c|c|c|c|c|c|}
\hline \multirow{2}{*}{ Sampel } & \multirow{2}{*}{$\begin{array}{c}\text { Length } \\
(\mathrm{mm})\end{array}$} & \multicolumn{4}{|c|}{ Peak } & \multirow{2}{*}{ Elongation } \\
\cline { 3 - 7 } & & $\mathrm{kgf}$ & $\mathrm{N}$ & $\mathrm{Kgf} / \mathrm{mm} 2$ & $\begin{array}{c}\mathrm{N} / \mathrm{m} 2 \times 10 \\
6\end{array}$ & \\
\hline 1. & 65.00 & 366.72 & 3515.35 & 4.70 & 46.34 & 4.04 \\
2. & 65.00 & 424.17 & 4181.72 & 4.88 & 47.98 & 3.56 \\
\hline
\end{tabular}

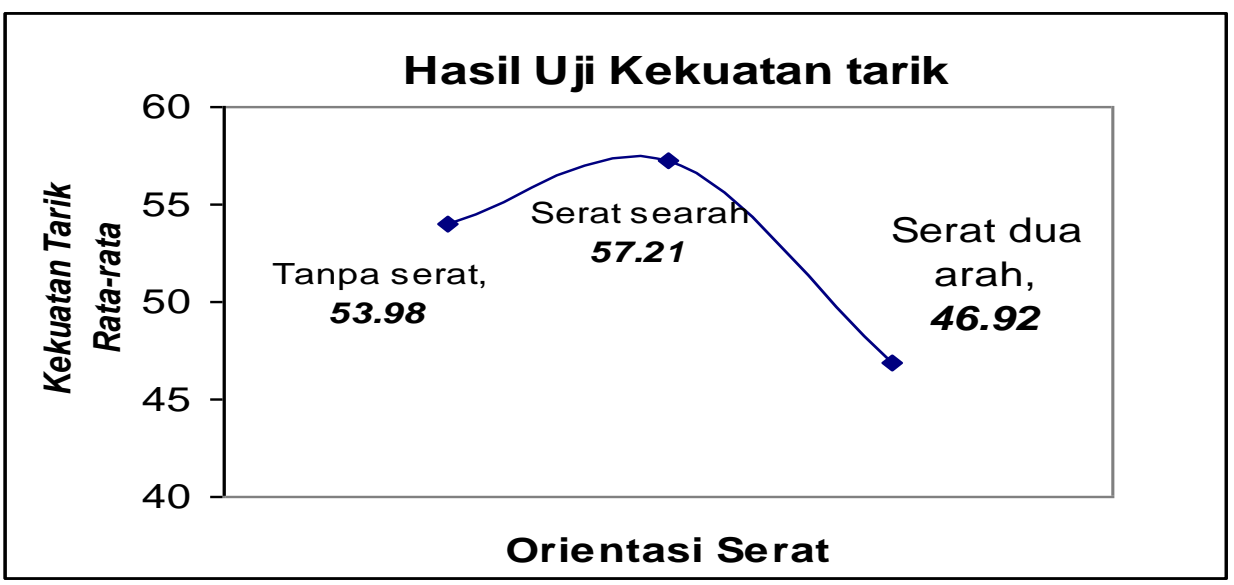

Gambar 4. Grafik hubungan kekuatan tarik dengan sampel pada bahan tanpa serat, orientasi serat searah dan serat dua arah single layer

Dari grafik kekuatan tarik sampel (gambar 4), dapat dilihat bahwa arah orientasi serat pada sampel memberikan pengaruh terhadap sifat mekanik komposit terutama kekuatan tarik. Kekuatan tarik terbesar terjadi pada komposit dengan arah serat searah single layer, kemudian komposit tanpa 
serat dan komposit serat dua arah single layer. Hal ini dapat dijelaskan secara mikroskopis dengan melihat analisa tegangan yang bekerja pada komposit.

Gambar 5, ditunjukan arah gaya yang bekerja pada komposit. Sebuah gaya yang bekerja pada sumbu c dikatakan sebagai gaya arah longitudinal seperti yang dilakukan pada penelitian ini. Arah orientasi merupakan hal penting dalam penguatan komposit. Karena arah orientasi serat berkaitan erat dengan penyebaran gaya yang bekerja pada komposit. Distribusi dari serat paling maksimum jika arah serat paralel dengan arah pembebanan. Kekuatan komposit akan berkurang dengan perubahan sudut dari serat, sehingga komposit akan mempunyai kekuatan yang tinggi jika struktur serat dan gaya yang bekerja adalah searah. Sedangkan kekuatannya akan melemah jika struktur arah keduanya berlawanan atau tegak lurus. Hal ini dikarenakan matrik komposit sebenarnya tidak mempunyai ikatan secara kimia dengan serat pengisinya melainkan hanya terjadi ikatan antar muka (ikatan secara fisika).

Karena itu, dalam penelitian ini diperoleh bahwa untuk serat yang searah single layer mempunyai kekuatan tarik terbesar, hal ini dikarenakan serat tersebut searah dengan gaya yang bekerja pada komposit. Sedangkan komposit dengan orientasi serat dua arah single layer atau saling tegak lurus mempunyai kekuatan tarik terkecil, karena arah seratnya transversal sehingga lebih mudah patah. Serat yang transversal dengan arah pembebanan tidak memberi penguatan, malah akan memperlemah. Hal ini karena antara serat yang searah dan serat yang melintang atau tegak lurus tidak terjadi ikatan antar muka (serat-serat) yang melawan gaya pada komposit. Ketika gaya makin besar beberapa serat mulai lepas (debonding) karena adanya tarikan gaya pada ujungnya. Akibat gaya antar muka antara serat dengan matrik makin lemah sehingga terjadi debonding yakni lepasnya ikatan antara serat dengan matriknya.

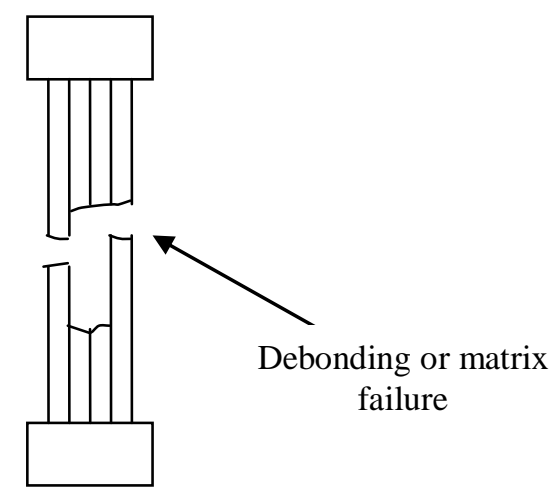

Gambar 5. Kerusakan sampel setelah uji tarik

Karena adanya gaya ikat antara matrik dengan serat ini, juga dapat menjelaskan mengapa komposit serat dua arah mempunyai kekuatan tarik yang kecil. Hal ini karena daya ikat antara serat (tegak lurus dengan pembebanan) dengan matriknya lemah bahkan lebih lemah daripada ikatan atom dalam matrik sendiri. Akibatnya ketika mendapat pembebanan terdapat gaya geser pada matriknya yang kemudian matrik lepas dari ikatan seratnya. Karena arah serat pada komposit ini (serat yang searah dan tegak lurus dengan arah 
pembebanan) tidak ada ikatan maka seluruh gaya akhirnya mengalami pemutusan atau patah.

Selain itu juga hasil pengujian menginformasikan beban maksimal yang dapat diterima oleh bahan sampel serta elongasi bahan sampel yang merupakan porsentase (\%) pertambahan panjang yang dialami oleh bahan uji sampai bahan tersebut putus/patah. Pada pengujian sampel polypropylene, beban awal yang diberikan pada setiap sampel sebesar 1961,17 N.

Berdasarkan grafik 4, beban maksimal yaitu 424,17 kgf pada puncak tertinggi dan dalam interval waktu yang cepat, yaitu 0,05 detik menjadi $360 \mathrm{kgf}$. Pada detik ke-0,4 sampai ke-1,9 rata-rata beban yang diberikan mengalami peningkatan hingga sampel batang uji mengalami kegentingan dan akhirnya putus atau patah pada detik ke-3,2.
Pertambahan panjang atau elongation yang didapat pada sampel uji serat dua arah adalah sebesar $3.56 \%$.

Dari tabel 1, 2 dan 3, untuk masing-masing sampel uji diperoleh data bahwa elongation terbesar terdapat pada sampel uji tanpa serat. Elongation terjadi pada materi atau komposit yang mempunyai sifat plastik, dimana terjadi pertambahan panjang sampai terjadi peristiwa pemutusan. Waktu terlama untuk sampai menuju pemutusan terdapat pada sampel tanpa serat. Ini membuktikan sifat polypropylene atau polimer termoplastik bersifat lemah dan ulet dibanding dengan bahan kompositnya. Kekakuan komposit (matrik+serat penguat) lebih besar daripada polimer PP atau matriknya. Elogation untuk setiap sampel adalah sebagai berikut:

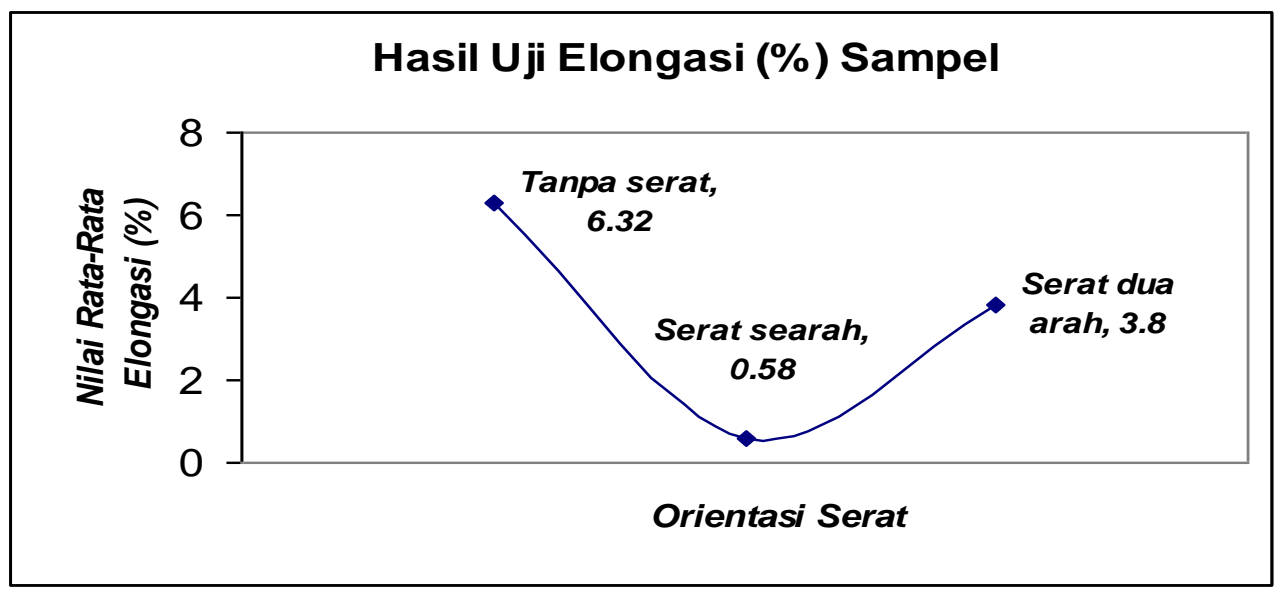

Gambar 6. Kerusakan sampel setelah uji tarik

Dari gambar 6 dapat dilihat bahwa nilai elongation komposit serat dua arah lebih besar daripada komposit serat searah yang berkebalikan dari nilai kekuatan uji tariknya. Elongation dapat dikatakan sebagai kemuluran (pertambahan panjang), yaitu arah serat tegak lurus ternyata memberikan tingkat kemuluran atau elongation yang lebih besar daripada arah serat yang searah. Komposit dengan orientasi serat searah mempunyai nilai kekuatan tarik yang besar dan mempunyai tingkat perpanjangan atau elogation yang rendah dibanding dengan komposit orientasi serat dua arah single layer. Begitu juga sebaliknya komposit dua arah mempunyai kekuatan tarik yang rendah dan elongation yang besar dibanding dengan komposit orientasi serat searah single layer. 


\section{Simpulan dan Saran \\ Simpulan}

Dari data penelitian dapat disimpulkan bahwa:

1. Berdasarkan uji kualitas ikatan antar muka atau kompaktibilitas komposit polypropylene dengan fiber Glass secara teoritis sudah terjadi kompaktibilitas antara kedua bahan tersebut sehingga membentuk bahan komposit, hal ini ditunjukan oleh grafik upper lower bond.

2. Dari hasil uji kekuatan tarik diperoleh, kekuatan tarik terbesar terdapat pada komposit dengan orientasi serat searah dibanding komposit tanpa serat $(1,06: 1)$ dan tanpa serat dibanding serat dua arah (1:0,87). Komposit dengan serat dua arah mempunyai kekuatan tarik terendah, hal ini disebabkan oleh arah serat yang tegak lurus dengan arah pembebanan akan memperlemah kekuatan tariknya, hal berkebalikan dengan nilai elogationnya yaitu orientasi serat dua arah mempunyai elongation yang lebih besar daripada serat searah.

\section{Saran}

Dalam pembuatan sampel uji diharapkan menggunakan alat yang dapat mengontrol suhu (stabil). Untuk penelitian selanjutnya diharapkan dapat dilakukan penelitian untuk komposit multilayer dengan perbedaan orientasi serat pada tiap lapisnya.

\section{Daftar Pustaka}

William D. Callister Jr. 2003. Material science and Engineering an Introduction. United State of America.
The University of Utah. John Willey and Sons, Inc.

Widyaningsih . 2006 . Uji kekuatan tarik pada polypropylene berpenguat fiber glass dengan orientasi searah dan dua arah single layer.Tidak dipublikasikan . UNESA Surabaya

Asrori. MZ. 2000.Fisika Polimer. ITS. Surabaya.

Djaprie, Sriati. 2000. Metalurgi Fisik Modern dan Rekayasa Material. Jakarta:Erlangga.

Djaprie, Sriati. 1985. Ilmu dan Teknologi bahan. Jakarta:Erlangga.

Dyah Kurnia Susanti. 2004. Uji Sifat Mekanik Komposit Poliester yang diperkuat Serat Bambu dengan Arah Serat Searah dan Dua Arah. Tidak dipublikasikan. UNESA. Surabaya.

Ika Setyaningsih Dhidhin. 2004. Pengaruh Penambahan Filler Aluminium Oxide (Al2O3) terhadap kekuatan tarik bahan polietilen jenis Low Density Polyethylen (LDPE). Tidak dipublikasikan. UNESA. Surabaya.

Mardewanti, Endah. 2003. Pengaruh Orientasi Serat Filler dan Lama Pemanasan terhadap Sifat Mekanik Polimer Resin Polyester Yucalak BQTNEX berpenguat Serat Bambu. Tidak dipublikasikan. UNESA. Surabaya.

Rajendra, V: A, Marikani. 2004. Material Science. New Delhi. Tata Mc Graw Hill. Surdia Prof. Dr.Tata: Saito, Prof Dr. Sinroku. 1999. Pengetahuan Bahan Teknik. PT.Pradnya Paramita. Jakarta.

http://www.courses.ahc.umn.edu/medicalsc hool/BMEn/5001/notes/fiberglass.htm 